\title{
Heritabilities, proportions of heritabilities explained by GWAS findings, and implications of cross-phenotype effects on PR interval
}

\author{
Claudia Tamar Silva ${ }^{1,2,3} \cdot$ Jan A. Kors ${ }^{4} \cdot$ Najaf Amin $^{1} \cdot$ Abbas Dehghan ${ }^{5}$. \\ Jacqueline C. M. Witteman ${ }^{5} \cdot$ Rob Willemsen ${ }^{6} \cdot$ Ben A. Oostra ${ }^{1,7}$. \\ Cornelia M. van Duijn ${ }^{1,7} \cdot$ Aaron Isaacs ${ }^{1,7}$
}

Received: 8 June 2015 / Accepted: 21 August 2015 / Published online: 18 September 2015

(C) The Author(s) 2015. This article is published with open access at Springerlink.com

\begin{abstract}
Electrocardiogram (ECG) measurements are a powerful tool for evaluating cardiac function and are widely used for the diagnosis and prediction of a variety of conditions, including myocardial infarction, cardiac arrhythmias, and sudden cardiac death. Recently, genome-wide association studies (GWASs) identified a large number of genes related to ECG parameter variability, specifically for the QT, QRS, and PR intervals. The aims of this study were to establish the heritability of ECG traits, including indices of left ventricular hypertrophy, and to directly assess the proportion of those heritabilities explained by GWAS variants. These analyses were conducted in a large, Dutch
\end{abstract}

Electronic supplementary material The online version of this article (doi:10.1007/s00439-015-1595-9) contains supplementary material, which is available to authorized users.

Aaron Isaacs

aaron.isaacs@gmail.com

1 Genetic Epidemiology Unit, Department of Epidemiology, Erasmus University Medical Center, PO Box 2040, 3000 CA Rotterdam, The Netherlands

2 Doctoral Program in Biomedical Sciences, Universidad del Rosario, Bogotá, Colombia

3 Department of Genetics (GENIUROS), Escuela de Medicina y Ciencias de la salud, Universidad del Rosario, Bogotá, Colombia

4 Department of Medical Informatics, Erasmus University Medical Center, Rotterdam, The Netherlands

5 Department of Epidemiology, Erasmus University Medical Center, Rotterdam, The Netherlands

6 Department of Clinical Genetics, Erasmus University Medical Center, Rotterdam, The Netherlands

7 Center for Medical Systems Biology, Leiden, The Netherlands family-based cohort study, the Erasmus Rucphen Family study using variance component methods implemented in the SOLAR (Sequential Oligogenic Linkage Analysis Routines) software package. Heritability estimates ranged from $34 \%$ for QRS and Cornell voltage product to $49 \%$ for 12-lead sum. Trait-specific GWAS findings for each trait explained a fraction of their heritability $(17 \%$ for QRS, $4 \%$ for QT, $2 \%$ for PR, $3 \%$ for Sokolow-Lyon index, and $4 \%$ for 12-lead sum). The inclusion of all ECG-associated single nucleotide polymorphisms explained an additional $6 \%$ of the heritability of PR. In conclusion, this study shows that, although GWAS explain a portion of ECG trait variability, a large amount of heritability remains to be explained. In addition, larger GWAS for PR are likely to detect loci already identified, particularly those observed for QRS and 12-lead sum.

\section{Introduction}

Parameters describing electrical activity in the heart, measured by the electrocardiogram (ECG), are important tools for diagnosing, monitoring, and evaluating risk in patients with cardiovascular disease (DeFilippis et al. 2007; Milan et al. 2010; Schwartz and Wolf 1978). ECG measurements, such as PR interval, QRS complex duration, and QT interval, are used for the diagnosis and prediction of cardiac arrhythmias and sudden cardiac death (SCD) (Dekker et al. 2004; Straus et al. 2006; Teodorescu et al. 2011). Myocardial depolarization and repolarization time is measured by the QT interval: the time between the onset of the QRS complex and the end of the T wave. QT shortening or prolongation has been associated with an increased risk for arrhythmias and SCD (Gussak et al. 2000; Straus et al. 2006). PR 
interval and QRS duration are measures of cardiac conduction time; QRS duration reflects conduction through the ventricular myocardium, while PR interval measures atrial and atrioventricular conduction from the sinoatrial node to the ventricular myocardium, primarily through the atrioventricular node (Smith et al. 2009). ECG calculations of the Sokolow-Lyon index (SL), the Cornell voltage product $(\mathrm{CV})$, and the 12-lead sum QRS product (12LS) have been used as indices of left ventricular hypertrophy (LVH) (Ang and Lang 2008; Molloy et al. 1992), which is a significant predictor of cardiovascular morbidity and mortality (Mayosi et al. 2002; Mutikainen et al. 2009a).

Several studies estimated a high heritability for RR interval (40-98 \%) and moderate heritabilities for QT/QTc (25$67 \%)$, PR (34-46\%), and QRS (33-43\%) (Dalageorgou et al. 2008; Eijgelsheim et al. 2009; Haarmark et al. 2011; Havlik et al. 1980; Holm et al. 2010; Im et al. 2009; Kolder et al. 2012; Mutikainen et al. 2009b; Russell et al. 1998; Smith et al. 2009). Only a few studies have estimated heritabilities for ECG indices of left ventricular hypertrophy, 12LS (32 \%), SL (36-57 \%), and CV (28-32 \%) (Mayosi et al. 2002; Molloy et al. 1992; Mutikainen et al. 2009a, b; Shah et al. 2011). Some of these estimates were generated in samples ascertained on the basis of phenotype or from special populations (such as SL and CV) (Havlik et al. 1980).

In recent years, a number of genome-wide association studies (GWASs) for ECG phenotypes identified 65 loci harboring both novel and previously described ECG genes, including two loci influencing electrocardiographic indices related to left ventricular hypertrophy (Arking et al. 2014; Eijgelsheim et al. 2009; Holm et al. 2010; Newton-Cheh et al. 2007, 2009; Nolte et al. 2009; Pfeufer et al. 2009, 2010; Shah et al. 2011; Sotoodehnia et al. 2010). Surprisingly, only a few of the novel loci include genes with established electrophysiological function (such as $A T P 1 B 1$ and $P L N$ and its negative regulator PRKCA (Arking et al. 2014; Barwe et al. 2009; Cerra and Imbrogno 2012; Medeiros et al. 2011)) and only a few have been confirmed through functional analysis (NDRG4 and SCN5A) (Chopra et al. 2010; Qu et al. 2008). These loci typically have small effects, individually accounting for only a small proportion of the variance of these traits. To date, no studies have directly estimated the extent to which these loci explain the trait heritabilities.

The first aim of the present study was to use a large, family-based cohort, not ascertained on the basis of phenotype, to estimate heritabilities for a number of widely used ECG traits. The second was to evaluate the proportion of heritability explained by genetic variants previously identified by GWAS.

\section{Methods}

\section{Study population}

This study was embedded in the Erasmus Rucphen Family study (ERF), a cohort derived from a region in the southwest of the Netherlands. The population was established in the middle of the 18th century by a limited number of founders, has experienced minimal immigration and emigration, and has exponentially increased in size in the last century. The ERF study was instituted in this population to determine the genes underlying quantitative trait variation in humans (Pardo et al. 2005). Interviews at the time of blood sampling were performed by medical practitioners and included questions on education level, smoking status, current medication use, and medical history (Sayed-Tabatabaei et al. 2005). Myocardial infarction was assessed through interview data and ECG measurements. Height and weight were measured with the participant in light underclothing and body mass index $\left(\mathrm{kg} / \mathrm{m}^{2}\right)$ was computed. Blood pressure was measured twice on the right arm in a sitting position after at least 5 min rest, using an automated device (OMRON 711, Omron Healthcare, Bannockburn, IL, USA). The average of the two measures was used in the analyses. Hypertension was defined through the use of antihypertensive medication and/or through the assessment of blood pressure measurements according to the World Health Organization guidelines (individuals with BP $\geq 140 / 90 \mathrm{mmHg}$ should be regarded as hypertensive) (1999; Mourad 2008; Tin et al. 2002). The Medical Ethics Committee of the Erasmus University Medical Center approved the ERF study protocol and all participants, or their legal representatives, provided written informed consent.

\section{ECG interpretation and measurement}

Examinations included 12-lead ECG measurements. A 10-s 12-lead ECG (on average, 8-10 beats) was recorded with an ACTA-ECG electrocardiograph (Esaote, Florence, Italy) with a sampling frequency of $500 \mathrm{~Hz}$. Digital measurements of the ECG parameters were made using the Modular ECG Analysis System (MEANS) (van Bemmel et al. 1990). In brief, MEANS operates on multiple simultaneously recorded leads, which are transformed to a detection function that brings out the QRS complex and the other parts of the signal. MEANS determines common onsets and offsets for all 12 leads together on one representative averaged beat, with the use of template matching techniques. The measurement and diagnostic performance of MEANS have been extensively evaluated, both by the developers and by others (de Bruyne et al. 1997; Willems et al. 1987, 1991) 
The MEANS criteria for MI are mainly based on pathological $\mathrm{Q}$ waves, QR ratio, and $\mathrm{R}$ wave progression (van Bemmel et al. 1990). A cardiologist, specialized in ECG methodology, ascertained the final diagnosis of MI.

MEANS was used to measure several ECG parameters (QRS, PR, and QT) and the three LVH proxies (SL, CV, and 12LS). Sokolow-Lyon was defined as the sum of the $\mathrm{S}$ wave in V1 plus the R wave in V5 or V6, Cornell as the sum of $\mathrm{R}$ in aVL and the S in V3, and 12-lead as the sum of $\mathrm{R}-\mathrm{S}$ in all 12 leads; these three voltages were then multiplied by QRS duration to obtain voltage-duration products as an approximation of the area under the QRS complex (Casale et al. 1985; Siegel and Roberts 1982; Sokolow and Lyon 1949). QT interval was adjusted for heart rate using Bazett's formula (Bazett 1920; Roguin 2011). All traits were adjusted for sex, age, BMI, height and heart rate (with the exception of QT), and rank transformed prior to analysis.

\section{Genotyping and SNP selection}

Genotyping in ERF was performed using Illumina $318 / 370 \mathrm{~K}$, Affymetrix $250 \mathrm{~K}$, and Illumina $6 \mathrm{~K}$ microarrays. Individuals were excluded for excess autosomal heterozygosity, mismatches between called and phenotypic gender, and if there were outliers identified by an IBS clustering analysis. The exclusion criteria for SNPs were Hardy-Weinberg equilibrium (HWE) $P \leq 10^{-6}$ or SNP call rate $\leq 98 \%$. After this quality control, measured genotypes which had minor allele frequencies $>1 \%$ were used to impute 2.5 million autosomal SNPs with the CEU samples from HapMap release 22 (build 36) as a reference panel with MACH version 1.0.16 (Li et al. 2010). GWAS for ECG traits have identified 71 index SNPs in 65 loci associated at the conventionally accepted significance threshold $\left(P<5.0 \times 10^{-8}\right)$ (Arking et al. 2014; Eijgelsheim et al. 2009; Holm et al. 2010; Marroni et al. 2009; NewtonCheh et al. 2005, 2007, 2009; Nolte et al. 2009; Pfeufer et al. 2009, 2010; Shah et al. 2011; Sotoodehnia et al. 2010) (catalog of published GWAS: http://www.genome. gov/gwastudies/). These SNPs were extracted from our imputed dataset for further analysis, with the exception of a single QRS SNP (rs991014). If multiple SNPs in a given locus were described in the GWAS, only the SNP with the lowest $P$ value was selected for inclusion.

\section{Statistical analysis}

Individuals were excluded from analysis if their ECG showed evidence of atrial fibrillation, myocardial infarction, left or right bundle branch block, or atrioventricular block. Additional exclusion criteria consisted of pacemaker implantation, Wolff-Parkinson-White syndrome, pregnancy, and use of Type I or III antiarrhythmic medications or digoxin, which may shorten the QT interval (Eijgelsheim et al. 2009). Individuals with QRS $>120 \mathrm{~ms}$ were excluded from the QRS, QT, and LVH proxy analyses. Those with $\mathrm{PR} \geq 320$ or $\leq 80 \mathrm{~ms}$ were excluded from the PR analyses. Those with QRS axis $>90$ or $<-30$ were excluded from the LVH proxy analyses. These exclusions were implemented to keep our data consistent with previous and ongoing GWAS.

Heritability estimates were obtained using a variance component approach based on maximum likelihood procedures implemented in the SOLAR (Sequential Oligogenic Linkage Analysis Routines) software package (http://www. sfbr.org/solar/index.html). A narrow-sense heritability estimate $\left(h^{2}\right)$ represents the fraction of variation in a trait attributable to additive genetic factors. To determine the proportion of variance due to genotypes associated with ECG trait variability, narrow-sense heritabilities were computed with and without genotypic data (Isaacs et al. 2007); comparison of the log likelihoods of these models using likelihood ratio tests allowed us to assess the significance of the differences. Heritabilities were calculated for each trait (QRS, QT, PR, SL, CV, 12LS) using three adjusted models. The first model adjusted only for non-genetic covariates, the second model included GWAS SNPs specific for each trait, and the third model included all of the ECG-associated SNPs. For the LVH proxies, only two SNPs for 12LS have been reported with genome-wide significance; since these measures are QRS products, the QRS SNPs were included in model 2 for these traits.

Inbreeding coefficients, which represent the level of consanguinity between a subject's parents, were calculated as previously described (Isaacs et al. 2007). To analyze the impact of inbreeding on the ECG traits, inbreeding coefficient quartiles were included in the SOLAR models. People with zero inbreeding were classed as " 0 "; the people with non-zero inbreeding were divided into quartiles. The quartiles were used because of the large skew in the distribution.

\section{Results}

After exclusions, 1396-1474 phenotyped and genotyped ERF participants were available for analysis. Table 1 shows descriptive statistics for a number of traits in the study population. The average age of the cohort was $47.5( \pm 13.8)$ years and $40 \%$ were men. The population tends toward being overweight, with a mean BMI of 26.7 $( \pm 4.5) \mathrm{kg} / \mathrm{m}^{2}$. A large number, nearly $30 \%$, were hypertensive. The median (inter-quartile range) of the pair-wise kinship coefficients for the analyzed sample was 0.004 (0.007); the number of pairs for a broad range of kinship 
Table 1 Descriptive statistics of the study population $(N=1474)$

\begin{tabular}{lcll}
\hline & Mean (SD) & Minimum & Maximum \\
\hline Males & $597(40 \%)$ & - & - \\
Age (year) & $47.2(13.9)$ & 16.6 & 81.4 \\
BMI (kg/m²) & $26.6(4.5)$ & 15.5 & 48.6 \\
Height (cm) & $166.6(9.0)$ & 143.6 & 196.5 \\
Weight (kg) & $74.0(14.8)$ & 41.9 & 154.7 \\
SBP (mmHg) & $136.0(19.5)$ & 85.5 & 217.0 \\
DBP (mmHg) & $79.8(9.8)$ & 54.5 & 120.0 \\
Hypertension & $629(42 \%)$ & - & - \\
QRS (ms) & $97.0(10.0)$ & 68 & 120 \\
QT (ms) & $397.4(27.7)$ & 300 & 520 \\
Heart rate (bpm) & $63.0(10.5)$ & 35 & 120 \\
PR (ms) & $152.3(22.1)$ & 92 & 308 \\
SL (mm ms) & $2316(680.2)$ & 1040.0 & 5288.5 \\
CV (mm ms) & $1172.6(498.3)$ & 118.7 & 3953.0 \\
12LS (mm ms) & $13,670(3551.6)$ & 5485 & 32,550 \\
\hline
\end{tabular}

Values presented are mean (SD) or $N(\%)$

$B M I$ body mass index, $S B P$ systolic blood pressure, $D B P$ diastolic blood pressure, $S L$ Sokolow-Lyon index, $C V$ Cornell product, $12 L S$ 12-lead sum product

levels are presented in Supplementary Table 1. The median (inter-quartile range) of the inbreeding coefficient was 0.003 (0.009). Correlations between the analyzed traits are presented in Table 2. The correlations between PR, QRS, and QT were modest, especially after adjustment for covariates. Correlations between the LVH proxies, particularly 12LS and SL, were stronger; these measures were also moderately correlated with QRS, a component of each.

The heritability for heart rate-adjusted QT, prior to the inclusion of SNP information, was $36 \%$ $\left(P=1.14 \times 10^{-8}\right)$. There was no evidence for recessive effects, as the inclusion of inbreeding coefficient did not alter the heritability estimates. The inclusion of SNPs specifically identified for QT (model 2) explained approximately $4 \%$ of the trait's heritability (leaving $96 \%$ unexplained) (Table 3). A significant difference between model 1 and 2 was observed $\left(P=2.58 \times 10^{-4}\right)$. The additional inclusion of SNPs identified in GWAS of other ECG phenotypes further decreased the heritability by $15 \%$, although this difference (between model 2 and 3 ) was not significant $(P=0.15)$.

The heritability of QRS was similar to that of QT, $34 \%$ $\left(P=2.32 \times 10^{-9}\right)$. QRS-specific GWAS SNPs explained $17 \%$ of the heritability of QRS $\left(P=1.30 \times 10^{-6}\right)$. Inclusion of non-QRS ECG SNPs did not further explain the heritability $(P=0.28)$. Two percent of the heritability of PR $\left(40 \%, P=4.13 \times 10^{-11}\right)$ could be explained by the inclusion of known PR variants $\left(P=2.64 \times 10^{-4}\right)$. The inclusion of SNPs associated with the other ECG phenotypes explained a further $6 \%$ of PR heritability, reducing it to $37 \%\left(P=1.00 \times 10^{-3}\right)$ (Table 3; Fig. 1). To investigate which set of SNPs might offer additional explanatory power for PR, comparisons were made with the addition of the QRS SNPs, the QT SNPs, and the 12LS SNPs in turn. This analysis determined that the majority of the additional PR heritability explained was due to the QRS SNPs (5\%, $\left.P=7.09 \times 10^{-4}\right)$, while the two 12LS SNPs explained an additional $0.5 \%\left(P=4.03 \times 10^{-4}\right)$.

Heritability estimates were also calculated for three LVH proxies (SL, CV, and 12LS); since only two GWAS associations (at $P<5 \times 10^{-8}$ ) are known for these traits, and since QRS is a crucial component of all three, QRS SNPs were included in model 2 for each of these measures. 12LS showed the highest heritability of these outcomes (49 \%, $P=4.6 \times 10^{-16}$ ), while $\mathrm{CV}$ showed the lowest (34 \%, $\left.P=7.44 \times 10^{-9}\right)$. The heritability estimate for SL was $46 \%\left(P=1.00 \times 10^{-13}\right)$; inclusion of QRS SNPs did not significantly alter this estimate $(P=0.42)$, nor did the inclusion of all ECG SNPs $(P=0.15)$. The inclusion of the two 12LS SNPs and the QRS SNPs explained $4 \%$ of the heritability of $12 \mathrm{LS}\left(P=5.77 \times 10^{-3}\right)$. The inclusion of the remainder of the SNPs did not further explain the heritability $(P=0.15)$. For $\mathrm{CV}$, the inclusion of the QRS SNPs increased the estimate slightly, but significantly $(0.7 \%$, $P=6.34 \times 10^{-5}$ ), while the inclusion of all SNPs did not influence the heritability $(P=0.18)$. The additional inclusion of inbreeding coefficient did not impact any of these models (data not shown).
Table 2 Pearson's correlations between ECG traits

\begin{tabular}{lllllll}
\hline & QRS & QT & PR & SL & CV & 12LS \\
\hline QRS & 1 & 0.225 & 0.144 & 0.376 & 0.468 & 0.532 \\
QT & 0.152 & 1 & 0.229 & 0.108 & 0.081 & 0.089 \\
PR & 0.007 & 0.105 & 1 & 0.082 & 0.169 & 0.117 \\
SL & 0.253 & 0.014 & 0.001 & 1 & 0.289 & 0.803 \\
CV & 0.382 & 0.053 & 0.04 & 0.178 & 1 & 0.564 \\
12LS & 0.409 & 0.034 & 0.019 & 0.741 & 0.484 & 1 \\
\hline
\end{tabular}

Above the diagonal: unadjusted correlations. Correlations are significant at the 0.01 level (2-tailed). Below the diagonal: adjusted correlations (adjusted for age, sex, body mass index, height and heart rate) 
Table 3 Heritability $\left(h^{2}\right)$ of ECG measurements

\begin{tabular}{|c|c|c|c|c|c|c|c|c|c|c|c|}
\hline & \multicolumn{2}{|l|}{ Model 1} & \multicolumn{5}{|l|}{ Model 2} & \multicolumn{4}{|l|}{ Model 3} \\
\hline & $h^{2}(\mathrm{SD})$ & $P$ & $h^{2}(\mathrm{SD})$ & $P$ & $\Delta h^{2 *}$ & $P_{\Delta h^{2}}$ & $\begin{array}{l}\text { n SNPS } \\
\text { REFS }\end{array}$ & $h^{2}(\mathrm{SD})$ & $P$ & $\Delta h^{2 * *}$ & $P_{\Delta h^{2}}$ \\
\hline QRS & $0.34(0.06)$ & $2.32 \times 10^{-9}$ & $0.28(0.06)$ & $1.30 \times 10^{-6}$ & 0.06 & $2.6 \times 10^{-3}$ & $21^{\mathrm{a}, \mathrm{b}}$ & $0.27(0.07)$ & $1.06 \times 10^{-5}$ & 0.01 & 0.28 \\
\hline QT & $0.36(0.07)$ & $1.14 \times 10^{-8}$ & $0.34(0.07)$ & $1.00 \times 10^{-7}$ & 0.02 & $2.5 \times 10^{-4}$ & $36^{\mathrm{a}, \mathrm{c}-\mathrm{f}}$ & $0.29(0.07)$ & $1.17 \times 10^{-5}$ & 0.05 & 0.15 \\
\hline PR & $0.40(0.06)$ & $4.13 \times 10^{-11}$ & $0.39(0.06)$ & $1.31 \times 10^{-10}$ & 0.01 & $2.6 \times 10^{-4}$ & $9^{\mathrm{a}, \mathrm{g}, \mathrm{h}}$ & $0.37(0.07)$ & $5.06 \times 10^{-9}$ & 0.02 & $1.0 \times 10^{-3}$ \\
\hline $12 \mathrm{LS}$ & $0.49(0.06)$ & $4.60 \times 10^{-16}$ & $0.46(0.06)$ & $1.44 \times 10^{-14}$ & 0.03 & $5.7 \times 10^{-3}$ & $23^{\mathrm{b}, \mathrm{i}}$ & $0.44(0.07)$ & $3.71 \times 10^{-12}$ & 0.02 & 0.15 \\
\hline $\mathrm{CV}$ & $0.34(0.07)$ & $7.44 \times 10^{-9}$ & $0.35(0.07)$ & $5.20 \times 10^{-9}$ & -0.002 & $6.3 \times 10^{-5}$ & $21^{\mathrm{b}}$ & $0.35(0.07)$ & $1.13 \times 10^{-8}$ & -0.005 & 0.17 \\
\hline SL & $0.46(0.07)$ & $1.00 \times 10^{-13}$ & $0.44(0.07)$ & $2.74 \times 10^{-12}$ & 0.02 & 0.42 & $21^{\mathrm{b}}$ & $0.43(0.07)$ & $6.76 \times 10^{-11}$ & 0.01 & 0.14 \\
\hline
\end{tabular}

Model 1: adjusted for age, sex, body mass index, height and heart rate. Model 2: adjusted for age, sex, body mass index, height, heart rate and SNPs associated with each trait. Model 3: adjusted for age, sex, body mass index, height, heart rate and SNPs associated with all traits (65 in total)

$h^{2}$ heritability, $n$ SNPS ${ }^{R E F S}$ number of SNPs and references, SL Sokolow-Lyon index, CV Cornell product, $12 L S$ 12-lead sum product

${ }^{a}$ Holm et al. (2010)

b Sotoodehnia et al. (2010)

c Arking et al. (2014)

d Marroni et al. (2009)

e Newton-Cheh et al. (2009)

f Pfeufer et al. (2009)

g Newton-Cheh et al. (2007)

${ }^{\mathrm{h}}$ Pfeufer et al. (2010)

${ }^{\mathrm{i}}$ Shah et al. (2011)

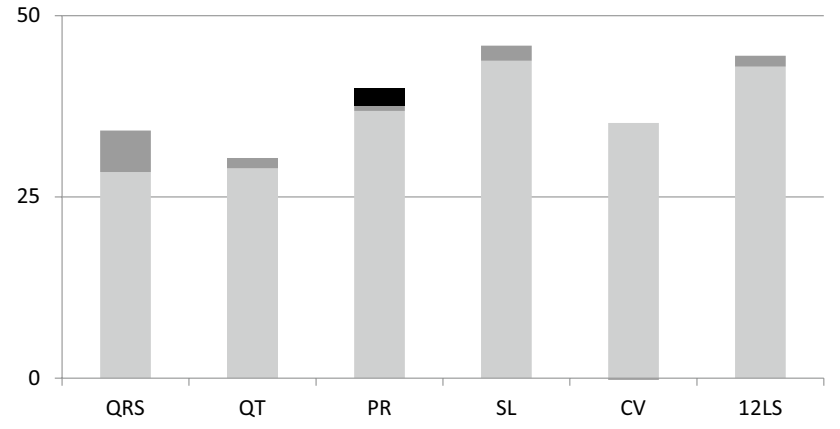

Fig. 1 Heritability $\left(h^{2}\right)$ of ECG measurements. The height of the bar indicates trait heritability. The proportion of unexplained heritability is in light gray and the proportion of heritability explained by traitspecific SNPs is depicted in dark gray. The additional proportion of the explained heritability of PR due to the inclusion of all ECG GWAS SNPs is in black

\section{Discussion}

In the present work, we estimated the heritability of ECG traits (QT, QRS, and PR) and ECG-derived LVH indices (SL, CV, and 12 LS). Highly significant estimates of heritability, ranging from 0.34 to 0.49 , were observed for all traits, several of which needed replication in a populationbased study. The inclusion of known trait-specific GWAS loci explained a fraction of the heritability of each trait except for SL and CV (17\% for QRS, $4 \%$ for QT, $2 \%$ for PR, $4 \%$ for 12LS). Inclusion of all ECG-associated SNPs further explained an additional proportion of the heritability for PR (6\%), clearly suggesting cross-phenotype effects for some loci.

This study benefits from a large, well-characterized, family-based population, selected on the basis of genealogy and not phenotype. It is well powered for this type of analysis and is not biased due to phenotypic selection for, as an example, cardiovascular disease. The complex genealogy allowed for the assessment of inbreeding and, furthermore, accounts for relatedness within families.

Despite these strengths, there are also limitations to this study. One is that ERF was part of the discovery analyses for the QRS and QT GWAS. However, ERF accounts for only a small proportion of those efforts, making it unlikely that over-fitting has a large impact on these findings. Discovery of genetic variants is still in progress. In all likelihood, larger GWAS efforts will lead to the identification of additional SNPs and, therefore, larger proportions of explained heritability. Finally, medication use, abundant in the population, may directly affect variability in ECG measurements. Some medications are known to induce such effects (Ahnve and Vallin 1982; Malik 2004), although, with the exception of the antiarrhythmics (which 
were excluded in these analyses), these effects are typically small or not well characterized. Moreover, any medication effects should be randomized across genotype groups, and, therefore, unlikely to affect these results.

Heritability estimates for QT between 60 and $67 \%$ have been reported in twin studies (Dalageorgou et al. 2008; Haarmark et al. 2011). Our estimate is substantially lower, but similar to that of another population-based family cohort, the Framingham study (35\%) (Newton-Cheh et al. 2005). This may be due to the inclusion of distant relatives in our study that share fewer household-based environmental factors (Sleegers et al. 2007). Our heritability estimate for QRS is higher than in the previous reports that did not find statistical significance (Havlik et al. 1980; Russell et al. 1998; Smith et al. 2009). Modest sample sizes or poor precision in the QRS measurements may have hindered those earlier studies (Havlik et al. 1980; Russell et al. 1998; Smith et al. 2009). Our estimate is somewhat lower than those reported in older women and a Chinese population (Eijgelsheim et al. 2009; Mutikainen et al. 2009b), but similar to that reported in an Icelandic population (Holm et al. 2010). Our findings for PR heritability are similar to those previously reported (Eijgelsheim et al. 2009; Smith et al. 2009). Among the LVH indices, our SL heritability estimate is less than previously reported in older women (Mutikainen et al. 2009b) and corresponds well to the estimate provided by Mayosi et al. (2002) $(\sim 40 \%)$ and Shah et al. (2011) ( 39 \%). With respect to CV, our estimate corresponds with previous estimates ranging from 23 to $40 \%$ (Mayosi et al. 2002; Shah et al. 2011). For 12LS, our estimate was higher $(0.46 \%)$ than previously reported $(0.32 \%)$ (Shah et al. 2011).

This is the first study that provides direct estimates of the proportion of heritability attributable to common variants discovered by GWAS. The heritability explained is particularly low for PR and SL, a finding that is not uncommon for complex traits (Manolio et al. 2009). For QRS (17\%), a substantial portion of trait heritability is explained by trait-specific GWAS variants, while for the other traits the proportion is more modest. At the same time, our study shows that large percentages remain unexplained (83\% for QRS, $96 \%$ for QT, $94 \%$ for PR, $94 \%$ for 12LS, $96 \%$ for SL, $100 \%$ CV). These percentages correspond to the "missing heritability". Several plausible reasons might explain this "missing heritability", including the overestimation of the heritability of these complex traits and the underestimation of the effects of common alleles identified through GWAS. It should also be noted that we have only studied the percentage of variance explained by one common variant in each locus. When more variants, including rare variants, are taken into account, these loci may explain a larger proportion of the heritability, as some loci are likely to include more than one independent association. Epigenetic modifications, regulated in part by microRNAs through regulation of DNA methyl transferases and histone deacetylases, are often dynamic and influenced by the environmental factors and may play a role. Finally, gene $\times$ gene interactions (epistasis) and gene $\times$ environment interactions might explain another portion of the heritability of these traits (Manolio et al. 2009; Marian 2012).

The finding that the addition of SNPs identified for another trait to the trait-specific SNPs explained an additional portion of heritability (particularly for the QRS SNPs and PR) strongly suggests the presence of variants with effects across these traits. These cross-phenotype effects are a common phenomenon in complex trait genetics (Solovieff et al. 2013). Known associations reinforce this notion; TBX5, for example, has been associated with QRS, PR, and QT (Holm et al. 2010), while SCN5A has been associated with both QRS and PR intervals (Pfeufer et al. 2010). This type of cross-phenotype effect was described by Sotoodehnia et al. (2010) who found several QRS loci previously associated with PR or QT intervals, including PLN, TBX5/3, and SCN10A/5A. It is of interest that cross-phenotype effects in particular decreased the heritability of PR.

In conclusion, we report heritability estimates for a number of ECG traits, including three LVH proxies. The incorporation of genotype information allowed for direct estimates of the impact of known GWAS SNPs on ECG trait heritabilities, and indicated that a high proportion of the genetic variability remains to be explained: the socalled "missing heritability". The inclusion of SNPs identified in GWAS of other ECG phenotypes further increased the amount of PR heritability that could be explained, clearly suggesting that GWAS variants identified for other ECG phenotypes (QRS and 12LS, in particular) influence $\mathrm{PR}$, despite failing to achieve genome-wide significance in PR GWAS to date. Increasing GWAS sample sizes, searching for cross-phenotype effects, and identifying less common variants are likely to increase the explicable portion of ECG trait heritability.

Acknowledgments The authors are grateful to all study participants, general practitioners, and neurologists for their contributions and to P. Veraart for her help in genealogy, Jeannette Vergeer for the supervision of the laboratory work, and P. Snijders for his help in data collection.

Open Access This article is distributed under the terms of the Creative Commons Attribution 4.0 International License (http://creativecommons.org/licenses/by/4.0/), which permits unrestricted use, distribution, and reproduction in any medium, provided you give appropriate credit to the original author(s) and the source, provide a link to the Creative Commons license, and indicate if changes were made. 


\section{References}

(1999) 1999 World health organization-international society of hypertension guidelines for the management of hypertension. Guidelines subcommittee. J Hypertens 17:151-183

Ahnve S, Vallin H (1982) Influence of heart rate and inhibition of autonomic tone on the QT interval. Circulation 65:435-439

Ang D, Lang C (2008) The prognostic value of the ECG in hypertension: where are we now? J Hum Hypertens 22:460-467. doi:10.1038/jhh.2008.24

Arking DE, Pulit SL, Crotti L, van der Harst P, Munroe PB, Koopmann TT, Sotoodehnia N, Rossin EJ, Morley M, Wang X, Johnson AD, Lundby A, Gudbjartsson DF, Noseworthy PA, Eijgelsheim M, Bradford Y, Tarasov KV, Dorr M, MullerNurasyid M, Lahtinen AM, Nolte IM, Smith AV, Bis JC, Isaacs A, Newhouse SJ, Evans DS, Post WS, Waggott D, Lyytikainen LP, Hicks AA, Eisele L, Ellinghaus D, Hayward C, Navarro P, Ulivi S, Tanaka T, Tester DJ, Chatel S, Gustafsson S, Kumari M, Morris RW, Naluai AT, Padmanabhan S, Kluttig A, Strohmer B, Panayiotou AG, Torres M, Knoflach M, Hubacek JA, Slowikowski K, Raychaudhuri S, Kumar RD, Harris TB, Launer LJ, Shuldiner AR, Alonso A, Bader JS, Ehret G, Huang H, Kao WH, Strait JB, Macfarlane PW, Brown M, Caulfield MJ, Samani NJ, Kronenberg F, Willeit J, Consortium CA, Consortium C, Smith JG, Greiser KH, Meyer Zu Schwabedissen H, Werdan K, Carella M, Zelante L, Heckbert SR, Psaty BM, Rotter JI, Kolcic I, Polasek O, Wright AF, Griffin M, Daly MJ, Dect/Edic, Arnar DO, Holm H, Thorsteinsdottir U, e MC, Denny JC, Roden DM, Zuvich RL, Emilsson V, Plump AS, Larson MG, O’Donnell CJ, Yin X, Bobbo M, D'Adamo AP, Iorio A, Sinagra G et al (2014) Genetic association study of QT interval highlights role for calcium signaling pathways in myocardial repolarization. Nat Genet 46:826-36. doi:10.1038/ng.3014

Barwe SP, Jordan MC, Skay A, Inge L, Rajasekaran SA, Wolle D, Johnson CL, Neco P, Fang K, Rozengurt N, Goldhaber JI, Roos KP, Rajasekaran AK (2009) Dysfunction of ouabain-induced cardiac contractility in mice with heart-specific ablation of $\mathrm{Na}$, K-ATPase beta1-subunit. J Mol Cell Cardiol 47:552-560

Bazett HC (1920) An analysis of the time-relations of electrocardiograms. Heart 7:353-370

Casale PN, Devereux RB, Kligfield P, Eisenberg RR, Miller DH, Chaudhary BS, Phillips MC (1985) Electrocardiographic detection of left ventricular hypertrophy: development and prospective validation of improved criteria. J Am Coll Cardiol 6:572-580

Cerra MC, Imbrogno S (2012) Phospholamban and cardiac function: a comparative perspective in vertebrates. Acta Physiol (Oxf). doi:10.1111/j.1748-1716.2012.02389.x

Chopra SS, Stroud DM, Watanabe H, Bennett JS, Burns CG, Wells KS, Yang T, Zhong TP, Roden DM (2010) Voltage-gated sodium channels are required for heart development in zebrafish. Circ Res 106:1342-1350

Dalageorgou C, Ge D, Jamshidi Y, Nolte IM, Riese H, Savelieva I, Carter ND, Spector TD, Snieder H (2008) Heritability of QT interval: how much is explained by genes for resting heart rate? J Cardiovasc Electrophysiol 19:386-391

de Bruyne MC, Kors JA, Hoes AW, Kruijssen DA, Deckers JW, Grosfeld M, van Herpen G, Grobbee DE, van Bemmel JH (1997) Diagnostic interpretation of electrocardiograms in populationbased research: computer program research physicians, or cardiologists? J Clin Epidemiol 50:947-952

DeFilippis AP, Larned JM, Cole JH, Nell-Dybdahl C, Miller JI 3rd, Sperling LS (2007) Clues to cardiovascular risk: an office-based approach. Prev Cardiol 10:36-41

Dekker JM, Crow RS, Hannan PJ, Schouten EG, Folsom AR, Study A (2004) Heart rate-corrected QT interval prolongation predicts risk of coronary heart disease in black and white middle-aged men and women: the ARIC study. J Am Coll Cardiol 43:565571. doi:10.1016/j.jacc.2003.09.040

Eijgelsheim M, Aarnoudse AL, Rivadeneira F, Kors JA, Witteman JC, Hofman A, van Duijn CM, Uitterlinden AG, Stricker BH (2009) Identification of a common variant at the NOS1AP locus strongly associated to QT-interval duration. Hum Mol Genet 18:347-357. doi:10.1093/hmg/ddn341

Gussak I, Brugada P, Brugada J, Wright RS, Kopecky SL, Chaitman BR, Bjerregaard P (2000) Idiopathic short QT interval: a new clinical syndrome? Cardiology 94:99-102

Haarmark C, Kyvik KO, Vedel-Larsen E, Budtz-Jorgensen E, Kanters JK (2011) Heritability of Tpeak-Tend interval and T-wave amplitude: a twin study. Circ Cardiovasc Genet 4:516-522. doi:10.1161/CIRCGENETICS.111.959551

Havlik RJ, Garrison RJ, Fabsitz R, Feinleib M (1980) Variability of heart rate, P-R, QRS and Q-T durations in twins. J Electrocardiol $13: 45-48$

Holm H, Gudbjartsson DF, Arnar DO, Thorleifsson G, Thorgeirsson G, Stefansdottir H, Gudjonsson SA, Jonasdottir A, Mathiesen EB, Njolstad I, Nyrnes A, Wilsgaard T, Hald EM, Hveem K, Stoltenberg C, Lochen ML, Kong A, Thorsteinsdottir U, Stefansson K (2010) Several common variants modulate heart rate, PR interval and QRS duration. Nat Genet 42:117-122. doi:10.1038/ng.511

Im SW, Lee MK, Lee HJ, Oh SI, Kim HL, Sung J, Cho SI, Seo JS, Kim JI (2009) Analysis of genetic and non-genetic factors that affect the QTc interval in a Mongolian population: the GENDISCAN study. Exp Mol Med 41:841-848

Isaacs A, Sayed-Tabatabaei FA, Aulchenko YS, Zillikens MC, Sijbrands EJ, Schut AF, Rutten WP, Pols HA, Witteman JC, Oostra BA, van Duijn CM (2007) Heritabilities, apolipoprotein E, and effects of inbreeding on plasma lipids in a genetically isolated population: the Erasmus Rucphen Family study. Eur J Epidemiol 22:99-105

Kolder IC, Tanck MW, Bezzina CR (2012) Common genetic variation modulating cardiac ECG parameters and susceptibility to sudden cardiac death. J Mol Cell Cardiol 52:620-629. doi:10.1016/j. yjmcc.2011.12.014

Li Y, Willer CJ, Ding J, Scheet P, Abecasis GR (2010) MaCH: using sequence and genotype data to estimate haplotypes and unobserved genotypes. Genet Epidemiol 34:816-834

Malik M (2004) Errors and misconceptions in ECG measurement used for the detection of drug induced QT interval prolongation. J Electrocardiol 37(Suppl):25-33

Manolio TA, Collins FS, Cox NJ, Goldstein DB, Hindorff LA, Hunter DJ, McCarthy MI, Ramos EM, Cardon LR, Chakravarti A, Cho JH, Guttmacher AE, Kong A, Kruglyak L, Mardis E, Rotimi CN, Slatkin M, Valle D, Whittemore AS, Boehnke M, Clark AG, Eichler EE, Gibson G, Haines JL, Mackay TF, McCarroll SA, Visscher PM (2009) Finding the missing heritability of complex diseases. Nature 461:747-753

Marian AJ (2012) Elements of 'missing heritability. Curr Opin Cardiol 27:197-201

Marroni F, Pfeufer A, Aulchenko YS, Franklin CS, Isaacs A, Pichler I, Wild SH, Oostra BA, Wright AF, Campbell H, Witteman JC, Kaab S, Hicks AA, Gyllensten U, Rudan I, Meitinger T, Pattaro C, van Duijn CM, Wilson JF, Pramstaller PP, Consortium E (2009) A genome-wide association scan of RR and QT interval duration in 3 European genetically isolated populations: the EUROSPAN project. Circ Cardiovasc Genet 2:322-328. doi:10.1161/CIRCGENETICS.108.833806

Mayosi BM, Keavney B, Kardos A, Davies CH, Ratcliffe PJ, Farrall M, Watkins H (2002) Electrocardiographic measures of left ventricular hypertrophy show greater heritability than echocardiographic left ventricular mass. Eur Heart J 23:1963-1971 
Medeiros A, Biagi DG, Sobreira TJ, de Oliveira PS, Negrao CE, Mansur AJ, Krieger JE, Brum PC, Pereira AC (2011) Mutations in the human phospholamban gene in patients with heart failure. Am Heart J 162(1088-95):e1

Milan DJ, Lubitz SA, Kaab S, Ellinor PT (2010) Genome-wide association studies in cardiac electrophysiology: recent discoveries and implications for clinical practice. Heart Rhythm 7:1141-1148

Molloy TJ, Okin PM, Devereux RB, Kligfield P (1992) Electrocardiographic detection of left ventricular hypertrophy by the simple QRS voltage-duration product. J Am Coll Cardiol 20:1180-1186

Mourad JJ (2008) The evolution of systolic blood pressure as a strong predictor of cardiovascular risk and the effectiveness of fixeddose $\mathrm{ARB} / \mathrm{CCB}$ combinations in lowering levels of this preferential target. Vasc Health Risk Manag 4:1315-1325

Mutikainen S, Ortega-Alonso A, Alen M, Kaprio J, Karjalainen J, Rantanen T, Kujala UM (2009a) Electrocardiographic indices of left ventricular hypertrophy and repolarization phase share the same genetic influences: a twin study. Ann Noninvasive Electrocardiol 14:346-354

Mutikainen S, Ortega-Alonso A, Alen M, Kaprio J, Karjalainen J, Rantanen T, Kujala UM (2009b) Genetic influences on resting electrocardiographic variables in older women: a twin study. Ann Noninvasive Electrocardiol 14:57-64

Newton-Cheh C, Larson MG, Corey DC, Benjamin EJ, Herbert AG, Levy D, D'Agostino RB, O'Donnell CJ (2005) QT interval is a heritable quantitative trait with evidence of linkage to chromosome 3 in a genome-wide linkage analysis: the Framingham Heart Study. Heart Rhythm 2:277-284

Newton-Cheh C, Guo CY, Wang TJ, O'Donnell CJ, Levy D, Larson MG (2007) Genome-wide association study of electrocardiographic and heart rate variability traits: the Framingham Heart Study. BMC Med Genet 8(Suppl 1):S7. doi:10.1186/1471-2350-8-S1-S7

Newton-Cheh C, Eijgelsheim M, Rice KM, de Bakker PI, Yin X, Estrada K, Bis JC, Marciante K, Rivadeneira F, Noseworthy PA, Sotoodehnia N, Smith NL, Rotter JI, Kors JA, Witteman JC, Hofman A, Heckbert SR, O'Donnell CJ, Uitterlinden AG, Psaty BM, Lumley T, Larson MG, Stricker BH (2009) Common variants at ten loci influence QT interval duration in the QTGEN study. Nat Genet 41:399-406. doi:10.1038/ng.364

Nolte IM, Wallace C, Newhouse SJ, Waggott D, Fu J, Soranzo N, Gwilliam R, Deloukas P, Savelieva I, Zheng D, Dalageorgou C, Farrall M, Samani NJ, Connell J, Brown M, Dominiczak A, Lathrop M, Zeggini E, Wain LV, Wellcome Trust Case Control C, Group DER, Newton-Cheh C, Eijgelsheim M, Rice K, de Bakker PI, consortium Q, Pfeufer A, Sanna S, Arking DE, consortium Q, Asselbergs FW, Spector TD, Carter ND, Jeffery S, Tobin M, Caulfield M, Snieder H, Paterson AD, Munroe PB, Jamshidi Y (2009) Common genetic variation near the phospholamban gene is associated with cardiac repolarisation: meta-analysis of three genome-wide association studies. PLoS One 4:e6138

Pardo LM, MacKay I, Oostra B, van Duijn CM, Aulchenko YS (2005) The effect of genetic drift in a young genetically isolated population. Ann Hum Genet 69:288-295

Pfeufer A, Sanna S, Arking DE, Muller M, Gateva V, Fuchsberger C, Ehret GB, Orru M, Pattaro C, Kottgen A, Perz S, Usala G, Barbalic M, Li M, Putz B, Scuteri A, Prineas RJ, Sinner MF, Gieger C, Najjar SS, Kao WH, Muhleisen TW, Dei M, Happle C, Mohlenkamp S, Crisponi L, Erbel R, Jockel KH, Naitza S, Steinbeck G, Marroni F, Hicks AA, Lakatta E, Muller-Myhsok B, Pramstaller PP, Wichmann HE, Schlessinger D, Boerwinkle E, Meitinger T, Uda M, Coresh J, Kaab S, Abecasis GR, Chakravarti A (2009) Common variants at ten loci modulate the QT interval duration in the QTSCD study. Nat Genet 41:407414. doi: $10.1038 / \mathrm{ng} .362$
Pfeufer A, van Noord C, Marciante KD, Arking DE, Larson MG, Smith AV, Tarasov KV, Muller M, Sotoodehnia N, Sinner MF, Verwoert GC, Li M, Kao WH, Kottgen A, Coresh J, Bis JC, Psaty BM, Rice K, Rotter JI, Rivadeneira F, Hofman A, Kors JA, Stricker BH, Uitterlinden AG, van Duijn CM, Beckmann BM, Sauter W, Gieger C, Lubitz SA, Newton-Cheh C, Wang TJ, Magnani JW, Schnabel RB, Chung MK, Barnard J, Smith JD, Van Wagoner DR, Vasan RS, Aspelund T, Eiriksdottir G, Harris TB, Launer LJ, Najjar SS, Lakatta E, Schlessinger D, Uda M, Abecasis GR, Muller-Myhsok B, Ehret GB, Boerwinkle E, Chakravarti A, Soliman EZ, Lunetta KL, Perz S, Wichmann HE, Meitinger T, Levy D, Gudnason V, Ellinor PT, Sanna S, Kaab S, Witteman JC, Alonso A, Benjamin EJ, Heckbert SR (2010) Genomewide association study of PR interval. Nat Genet 42:153-159. doi:10.1038/ng.517

Qu X, Jia H, Garrity DM, Tompkins K, Batts L, Appel B, Zhong TP, Baldwin HS (2008) Ndrg4 is required for normal myocyte proliferation during early cardiac development in zebrafish. Dev Biol 317:486-496

Roguin A (2011) Henry Cuthbert Bazett (1885-1950) - the man behind the QT interval correction formula. Pacing Clin Electrophysiol 34:384-388. doi:10.1111/j.1540-8159.2010.02973.x

Russell MW, Law I, Sholinsky P, Fabsitz RR (1998) Heritability of ECG measurements in adult male twins. J Electrocardiol 30(Suppl):64-68

Sayed-Tabatabaei FA, van Rijn MJ, Schut AF, Aulchenko YS, Croes EA, Zillikens MC, Pols HA, Witteman JC, Oostra BA, van Duijn CM (2005) Heritability of the function and structure of the arterial wall: findings of the Erasmus Rucphen Family (ERF) study. Stroke 36:2351-2356. doi:10.1161/01.STR.0000185719.66735. dd

Schwartz PJ, Wolf S (1978) QT interval prolongation as predictor of sudden death in patients with myocardial infarction. Circulation 57:1074-1077

Shah S, Nelson CP, Gaunt TR, van der Harst P, Barnes T, Braund PS, Lawlor DA, Casas JP, Padmanabhan S, Drenos F, Kivimaki M, Talmud PJ, Humphries SE, Whittaker J, Morris RW, Whincup PH, Dominiczak A, Munroe PB, Johnson T, Goodall AH, Cambien F, Diemert P, Hengstenberg C, Ouwehand WH, Felix JF, Glazer NL, Tomaszewski M, Burton PR, Tobin MD, van Veldhuisen DJ, de Boer RA, Navis G, van Gilst WH, Mayosi BM, Thompson JR, Kumari M, MacFarlane PW, Day IN, Hingorani AD, Samani NJ (2011) Four genetic loci influencing electrocardiographic indices of left ventricular hypertrophy. Circ Cardiovasc Genet 4:626-635. doi:10.1161/CIRCGENETICS.111.960203

Siegel RJ, Roberts WC (1982) Electrocardiographic observations in severe aortic valve stenosis: correlative necropsy study to clinical, hemodynamic, and ECG variables demonstrating relation of 12-lead QRS amplitude to peak systolic transaortic pressure gradient. Am Heart J 103:210-221

Sleegers K, de Koning I, Aulchenko YS, van Rijn MJ, Houben MP, Croes EA, van Swieten JC, Oostra BA, van Duijn CM (2007) Cerebrovascular risk factors do not contribute to genetic variance of cognitive function: the ERF study. Neurobiol Aging 28:735-741

Smith JG, Lowe JK, Kovvali S, Maller JB, Salit J, Daly MJ, Stoffel M, Altshuler DM, Friedman JM, Breslow JL, Newton-Cheh C (2009) Genome-wide association study of electrocardiographic conduction measures in an isolated founder population: Kosrae. Heart Rhythm 6:634-641

Sokolow M, Lyon TP (1949) The ventricular complex in right ventricular hypertrophy as obtained by unipolar precordial and limb leads. Am Heart J 38:273-294

Solovieff N, Cotsapas C, Lee PH, Purcell SM, Smoller JW (2013) Pleiotropy in complex traits: challenges and strategies. Nat Rev Genet 14:483-495. doi:10.1038/nrg3461 
Sotoodehnia N, Isaacs A, de Bakker PI, Dorr M, Newton-Cheh C, Nolte IM, van der Harst P, Muller M, Eijgelsheim M, Alonso A, Hicks AA, Padmanabhan S, Hayward C, Smith AV, Polasek O, Giovannone S, Fu J, Magnani JW, Marciante KD, Pfeufer A, Gharib SA, Teumer A, Li M, Bis JC, Rivadeneira F, Aspelund T, Kottgen A, Johnson T, Rice K, Sie MP, Wang YA, Klopp N, Fuchsberger C, Wild SH, Mateo Leach I, Estrada K, Volker U, Wright AF, Asselbergs FW, Qu J, Chakravarti A, Sinner MF, Kors JA, Petersmann A, Harris TB, Soliman EZ, Munroe PB, Psaty BM, Oostra BA, Cupples LA, Perz S, de Boer RA, Uitterlinden AG, Volzke H, Spector TD, Liu FY, Boerwinkle E, Dominiczak AF, Rotter JI, van Herpen G, Levy D, Wichmann HE, van Gilst WH, Witteman JC, Kroemer HK, Kao WH, Heckbert SR, Meitinger T, Hofman A, Campbell H, Folsom AR, van Veldhuisen DJ, Schwienbacher C, O'Donnell CJ, Volpato CB, Caulfield MJ, Connell JM, Launer L, Lu X, Franke L, Fehrmann RS, te Meerman G, Groen HJ, Weersma RK, van den Berg LH, Wijmenga C, Ophoff RA, Navis G, Rudan I, Snieder H, Wilson JF, Pramstaller PP, Siscovick DS, Wang TJ, Gudnason V, van Duijn CM, Felix SB, Fishman GI, Jamshidi Y, Stricker $\mathrm{BH}$ et al (2010) Common variants in 22 loci are associated with QRS duration and cardiac ventricular conduction. Nat Genet 42:1068-1076

Straus SM, Kors JA, De Bruin ML, van der Hooft CS, Hofman A, Heeringa J, Deckers JW, Kingma JH, Sturkenboom MC, Stricker
BH, Witteman JC (2006) Prolonged QTc interval and risk of sudden cardiac death in a population of older adults. J Am Coll Cardiol 47:362-367. doi:10.1016/j.jacc.2005.08.067

Teodorescu C, Reinier K, Uy-Evanado A, Navarro J, Mariani R, Gunson K, Jui J, Chugh SS (2011) Prolonged QRS duration on the resting ECG is associated with sudden death risk in coronary disease, independent of prolonged ventricular repolarization. Heart Rhythm 8:1562-1567. doi:10.1016/j.hrthm.2011.06.011

Tin LL, Beevers DG, Lip GY (2002) Systolic vs diastolic blood pressure and the burden of hypertension. J Hum Hypertens 16:147150. doi:10.1038/sj.jhh.1001373

van Bemmel JH, Kors JA, van Herpen G (1990) Methodology of the modular ECG analysis system MEANS. Methods Inf Med 29:346-353

Willems JL, Arnaud P, van Bemmel JH, Bourdillon PJ, Degani R, Denis B, Graham I, Harms FM, Macfarlane PW, Mazzocca G et al (1987) A reference data base for multilead electrocardiographic computer measurement programs. J Am Coll Cardiol 10:1313-1321

Willems JL, Abreu-Lima C, Arnaud P, van Bemmel JH, Brohet C, Degani R, Denis B, Gehring J, Graham I, van Herpen G et al (1991) The diagnostic performance of computer programs for the interpretation of electrocardiograms. N Engl J Med 325:17671773. doi:10.1056/NEJM199112193252503 